\title{
A Inclusão física numa visão de acessibilidade para pessoas com deficiência física na rede municipal de ensino de Alto Alegre/RR-Brasil.
}

(A inclusão physics numa visão de acessibilidade for pessoas com deficiência física na municipal network of ensino de Alto Alegre / RR-Brazil).

Cavalcante de Sousa Selma, Maria Selma

Governo de Roraima (Brasil)

\section{Fecha recepción: 01-10-2018}

Páginas 01-18

Fecha aceptación: 30-11-2018

\section{Resumen.}

Una significativa parte de la población brasileña posee algún tipo de discapacidad, y muchos de ellos están insertos en las escuelas públicas, algunos con discapacidad física no pueden vivir en condiciones de dignidad debido a obstáculos y barreras arquitectónicas presentes en el medio escolar, dificultando la inclusión de los alumnos en las escuelas. Es necesario crear oportunidades igualitarias, se hace necesario que haya una adaptación en las edificaciones y estructuras de los equipos de interés público para que les permita un mayor acceso de los alumnos, para que éstos puedan ejercer su ciudadanía con dignidad. En este sentido, el interés por la presente investigación surgió de la necesidad de analizar la accesibilidad arquitectónica para los alumnos con discapacidad física de la red municipal de enseñanza de Alto Alegre / RR, reflexionando sobre las escuelas que están o no adaptadas y preparadas para este proceso. Se trata de una investigación investigadora, no experimental, descriptiva y exploratoria, con el paradigma de enfoque cualitativo con el propósito de explicitar concepto sobre la accesibilidad arquitectónica en una visión inclusiva. La información recolectada permite considerar que las escuelas de la red municipal de enseñanza de Alto Alegre / Brasil, se encuentran desprovistas de adaptaciones, estructuras capaces de atender las necesidades a los alumnos con discapacidad física, implicando directamente en el proceso inclusivo de esos alumnos.

Palabras clave: accesibilidad arquitectónica; deficiencia física; inclusión

\begin{abstract}
.
A significant portion of the Brazilian population has some type of disability, and many of them are inserted in public schools, some with physical disabilities can not live in dignified conditions due to obstacles and architectural barriers present in the school environment, making it difficult to include students in schools. It is necessary to create equal opportunities, it is necessary that there is an adaptation in the buildings and structures of the equipment of public interest so that it allows them greater access of the students, so that they can exercise their citizenship with dignity. In this sense, interest in this research arose from the need to analyze architectural accessibility for students with physical disabilities in the Alto Alegre / RR municipal school system, reflecting on the schools that are or are not adapted and prepared for
\end{abstract}


this process. It is an investigative, non-experimental, descriptive and exploratory research, with the qualitative focus paradigm in order to explain the concept of architectural accessibility in an inclusive view. The collected information allows to consider that the schools of the municipal network of Alto Alegre / Brazil, are devoid of adaptations, structures able to meet the needs of students with physical disabilities, implying directly in the inclusive process of these students.

Keywords: architectural accessibility; physical impairment; inclusion

\section{1.-Introducción.}

Educação Inclusiva é um conceito abrangente, que envolve não somente o processo de inclusão das pessoas com deficiência ou de Transtorno Globais de desenvolvimento na rede comum de ensino em todos os seus graus, mas, fundamentalmente, todas as diferenças possíveis entre as pessoas. De fato, entende-se que cada ser humano é único, e as oportunidades devem ser iguais para todos Soler, (2005). Nesta perspectiva, a discussão a cerca da educação inclusiva leva a sociedade concebê-la como um caminho para o desenvolvimento social, tendo em vista que um trabalho significativo realizado nas instituições implica em ações direcionadas, com respeito às especificidades e diversidades humanas. Desta forma, apresenta-se a acessibilidade como fator integrante do processo inclusivo, assim sendo, constitui um desafio para assegurar as pessoas com deficiência física oportunidades igualitárias, com dispositivos que garantem a adequação acessível a todos os ambientes. Na busca por uma sociedade mais justa e igualitária, respeitando a diversidade de cada. Diante desses pressupostos, esta pesquisa se propõe analisar a acessibilidade arquitetônica para os alunos com deficiência física da rede municipal de ensino de Alto Alegre/RR, refletindo sobre as escolas que estão ou não adaptadas e preparadas para este processo. Para tal, buscou-se com base nos autores Dischinger et. al. (2004; 2007) Mantoan (2006), Figueiredo (2010), Bersch e Sartoretto (2010), entre outros autores, que com suas obras forneceram informações suficientes para a análise da referida investigação.

\section{2.-A inclusão física numa visão de acessibilidade para pessoas com deficiência física na rede municipal de ensino de Alto Alegre/RR-Brasil.}

\section{1.-Acessibilidade arquitetônica.}

A palavra acessível vem do latim "acessibile", utilizada para qualificar adjetivos que significa a que se pode chegar a que se pode alcançar obter ou possuir. A norma Brasileira ABNT NBR 9050(2004) define a acessibilidade como sendo a possibilidade e condição de alcance, percepção e entendimento para a utilização com segurança e autonomia de edificações, espaço, mobiliário ou equipamento urbano. Segundo Bersch e Sartoretto:

A existência de barreiras físicas de acessibilidade nas escolas brasileira e em seus entornos é histórica. Não somente as escolas, mas as próprias cidades, incluídos aí os serviços de transporte e de 
infraestrutura, têm sido responsáveis pelo isolamento e segregação das pessoas com deficiência em instituições e até em suas próprias casas. Acessibilidade deve ser vista como parte de uma política de mobilidade que promova 0 direito de todos a todos os espaços, inclusive, e principalmente, as escolas. O Brasil passou por profundas mudanças relacionadas às políticas públicas voltadas para as pessoas com deficiências nos últimos dez anos. Bersch e Sartoretto (2010, p.35).

Com esta percepção, entendemos a grande necessidade de repensarmos 0 ambiente escolar para todos, buscando direcionar e visualizar uma escola que possibilite a inserção das diversas pessoas, que possuem algum tipo de limitação, neste caso em especial, a física, para que possa estar, juntamente com as demais, fazendo jus de seus direitos constituídos e legitimados pela constituição federal.

\section{2.-Legislação básica.}

Segundo a Constituição Federal (BRASIL, 1988, ):

Art. $5^{a}$ Todos são iguais perante a lei, sem distinção de qualquer natureza, garantindo-se aos brasileiros e aos estrangeiros residentes no país à inviolabilidade ao direito à vida, à liberdade, à segurança $\mathrm{e}$ a propriedade...(p.05);

Art. 208, III, "Atendimento educacional especializado aos deficientes, de preferência na rede regular de ensino" (p.43);

Art.227, $\S I^{\circ}$ II, "Criação de programas de prevenção e atendimento especializado para as pessoas portadoras de deficiência física, sensorial ou mental, bem como de integração social do adolescente e do jovem portador de deficiência, mediante 0 treinamento para 0 trabalho e a convivência, e a facilitação do acesso aos bens e serviços coletivos, com a eliminação de obstáculos arquitetônicos e de todas as formas de discriminação" (p.45).

A Política Nacional para Integração da Pessoa Portadora de Deficiência estabelecida pela Lei 7.853 , de 24 de Outubro de 1989, cuja lei é regulamentada pelo Decreto 3.298/99 (BRASIL, 1999), assegura o direito das pessoas com deficiência, além de efetiva inclusão social.

Segundo a Lei 7.853, de 24 de Outubro de 1989:

Art. $2^{\circ}$ Ao Poder Público e seus órgãos cabe assegurar às pessoas portadoras de deficiência o pleno exercício de seus direitos básicos, inclusive dos direitos à educação, à saúde, ao trabalho, ao lazer, à previdência social, ao amparo à infância e à maternidade, e de outros que, decorrentes da Constituição e das leis, propiciem seu bem-estar pessoal, social e econômico. (p. 01).

O Estatuto da Criança e do Adolescente, disposto na Lei 8.069 de 13 de julho de 1990 assegura a proteção integral à criança e ao adolescente, conforme nos artigos abaixo: 
Art. $53 \mathrm{~A}$ criança e 0 adolescente têm direito à educação, visando 0 pleno desenvolvimento de sua pessoa, preparo para o exercício da cidadania e qualificação para o trabalho, assegurando-lhes:

I- Igualdade de condições para o acesso e permanência na escola (p.39);

II- "Direito de ser respeitado por seus educadores(p.39);

V- Acesso a escola publica e gratuita próximo de sua residência (pag.39).

A Lei 10.098/00 estabelece normais gerais e critérios básicos para promoção da acessibilidade das pessoas portadoras de deficiência ou com mobilidade reduzida, neste sentido, busca eliminar barreiras e obstáculos nas vias e espaços públicos, na construção e reforma de edifícios tal como nos meios de transporte e comunicação, Brasil, (2000)

A lei $10.048 / 00$ prioriza 0 atendimento às pessoas com deficiência física pelas empresas públicas de transporte e concessionárias de transporte coletivo, Brasil, (2000).

A Lei 7.405/85 torna obrigatória a colocação do Símbolo Internacional de Acesso em todos os locais e serviços que permitam sua utilização por pessoas com deficiência em locais que possibilitem o acesso, a circulação e a utilização por pessoas portadoras de deficiência, Brasil, (1985).

Em termo de legislação, o Brasil encontra-se respaldado, é um país adiantado em relação aos demais, o que representa aos brasileiros uma vantagem quanto ao desenvolvimento do país, embora que nem sempre estes dispositivos legais estão disponíveis a todos.

\section{3.-Deficiência Física.}

Conforme Ministério da Educação e Cultura - Secretaria de Educação Especial, os alunos com deficiência física são aqueles que:

[...] apresentam alterações musculares, ortopédicas, articulares ou neurológicas que podem comprometer seu desenvolvimento educacional. Quando estas alterações acarretarem dificuldades no processo de aprendizagem, 0 aluno deve receber atendimento psicopedagógico, recursos didáticos adaptados e equipamentos especiais que facilite seu processo de construção de conhecimento.(Brasil, 2006).

No Decreto no 3.298 da legislação brasileira, encontramos o conceito de deficiência física, conforme segue:

Art. $3^{\circ}$ Para os efeitos deste decreto, considera-se:

1-Deficiência- toda perda ou normalidade de uma estrutura ou função psicológica, fisiológica ou anatômica que gere incapacidade para 0 desempenho da atividade, dentro do padrão considerado normal para o ser humano.(Brasil, 1999, p.04)

2-Deficiência física - alteração completa ou parcial de um ou mais segmento do corpo humano, acarretando o comprometimento da função física, apresentando-se sob a forma de paraplegia, 
paraparesia, monoplegia, triparesia, hemiplegia, hemiparesia cerebral, membros com deformidades estéticas e as que não produzam dificuldades para o desempenho da função.(Brasil, 1999, p. 04)

Ainda segundo Schimer, et al:

O comprometimento da função física poderá acontecer quando existe a falta de um membro (amputação), sua má-formação ou deformação (alteração que acometem o sistema muscular e esquelético. (Schimer, 2007, p.22).

2.4.-Inclusão, uma possível realidade.

Educação Inclusiva é um conceito abrangente, que envolve não somente o processo de inclusão das pessoas com necessidades especiais ou de Transtorno Globais de desenvolvimento na rede comum de ensino em todos os seus graus, mas, fundamentalmente, todas as diferenças possíveis entre as pessoas. De fato, entende-se que cada ser humano é uno, e as oportunidades devem ser iguais para todos Soler, (2005). Deve-se ressaltar que a inclusão implica uma mudança de paradigma educacional, à medida que exige uma reorganização das práticas escolares: planejamentos, formação de turmas, currículo, avaliação e gestão do processo avaliativo, Mantoan (2005).

Conforme o Ministério da Educação e Cultura-Secretaria de Educação Especial (2000), percebemos ao longo da história da humanidade, as pessoas com deficiência perpassaram por vários períodos, entre eles o de exclusão e o de repúdio social foram mais notório e a sociedade os tratavas de várias formas, na antiguidade, por exemplos, eram característicos o infanticídio e 0 abandono de crianças nascidas com deficiências. Já na Idade Média, essas mesmas pessoas passaram a representar uma fonte de diversão ou de expiação de pecados. A Bíblia, por exemplo, traz referências de cegos, mancos e leprosos - sendo muitos deles representados como pedintes ou como indivíduos rejeitados pela comunidade, que assim agia por medo de suas doenças ou pela crença de que fossem uma encarnação do demônio (p.13). Concebemos a educação inclusiva na proposta do Atendimento Educacional Especializado como uma possibilidade de inclusão dos alunos com necessidades especiais, mas entendemos ainda, que há uma grande defasagem entre 0 ideal contido na legislação e a realidade da discriminação e segregação, neste sentido a escola inclusiva é conceituada como:

Aquela em que todos e cada um dos alunos têm o seu lugar na sala de aula, integra-se à convivência com pares etários diversificados, sendo aceito como um indivíduo, do modo como é, sem ser preciso apresentar uma característica predeterminada que venha a definir a qual agrupamento ele deveria pertencer. (Guenther, 2003, p.46)

Figueiredo (2010) ressalta a necessidade de a escola conceber o aluno como um indivíduo com características próprias, respeitando-os conforme sua diversidade, estilo de vida, ritmo e nível de desenvolvimento. 
A década de 90 trouxe a proposta de educação para todos, a partir do compromisso assumido pelas nações que compareceram à Conferência Mundial da UNESCO, realizada em Jomtien/Tailândia. O Brasil, tendo assumido essa proposta, passa a pensar na transformação do sistema educacional para acolher a todos, com igualdade de qualidade e condições.

Em 1994, ocorre em Salamanca, na Espanha, uma convenção que resulta no documento chamado Declaração de Salamanca, cujo conteúdo reflete 0 compromisso dos países participantes com a inclusão de alunos com necessidades especiais e a construção da escola inclusiva. O Brasil adota a proposta e assume 0 compromisso com a construção da escola inclusiva, adotando políticas e assumindo estratégias para a efetivação dessa concepção de educação. A partir daí, a Lei Diretrizes e Bases da Educação Nacional 9394/965 reformula o sistema de ensino no país, com vistas à atenção para a constituição de uma escola inclusiva aberta e para a aceitação de todos os alunos, principalmente daqueles com necessidades especiais.

Neste sentido, concebe-se a inclusão como uma possibilidade de participação de todos os indivíduos no processo escolar, estes independe de sua condição física, psíquica ou emocional, todos são iguais perante a lei.

\section{3.-Metodologia}

A abordagem utilizada na investigação foi qualitativa, a qual se propôs, realizar uma pesquisa sobre a acessibilidade arquitetônica para alunos com deficiência física da rede municipal de ensino de Alto Alegre, analisando as escolas no que compete sua estrutura física acordados numa visão inclusiva, buscando refletir sobre a importância de um ambiente propicio a todos, sem limitações, sem barreiras e acima de tudo, com uma proposta que alcance todas as especificidades existente no ambiente escolar.

\section{1-Participantes.}

Para a realização do estudo foram selecionados Escolas, Professores, Diretores e Secretária de Educação, da rede municipal de ensino do município de alto Alegre/RR na intenção de colher informações que propusessem a este estudo garantia de forma a atender todos os critérios necessário para alcançar os objetivos propostos na pesquisa.

\section{2-População Investigada.}

A Rede Municipal de Educação de Alto Alegre/RR é composta por 19 (dezenove) escolas, destas, 4 (quatro) escolas são considerada de porte médio, com gestores e coordenadores; 7 (sete) escolas são unidocentes, existe apenas um professor para ministrar todas as séries e disciplinas, isto devido a quantidade de alunos e essas escolas serem em localidades isoladas, frequentadas apenas por colonos de suas circunvizinhanças; 8 (oito) Escolas Indígenas, estas atendem apenas a modalidade infantil e também são consideradas de pequeno porte, com apenas uma sala de 
aula, dispensando a figura do gestor. Para a coletas de dados foram visitadas apenas as 04(quatros) escolas maiores, localizadas na apropria sede do município, zona urbana.

\section{3.-Amostra Investigada.}

Para que a pesquisa seja efetivada através de dados confiáveis, escolheu-se 04 (quatros) escolas por fazerem parte da rede municipal de ensino e serem um conjunto de elementos viáveis a observações previamente estabelecidas por indicadores e critérios. Foram selecionados ainda, a Secretária de educação Municipal, por entender-se que a mesma estar envolvido diretamente com as escolas e é a principal responsável pelas as mesmas, 04 (quatro) gestores das referidas escolas, pelo comprometimento com as atividades envolvidas no âmbito escolar, sendo os principais responsáveis em conduzir o processo dessas escolas, 34 (trinta e quatro) professores que compõem o quadro de docente das escolas investigadas, por estarem ligados diariamente com o processo educacional dos alunos com deficiência física. A seleção da amostra supracitada se deu pelas especificidade de cada indivíduo e o seu respectivo envolvimento com os segmentos da pesquisa.

Neste sentido, a amostra não-probabilísticas resulta de uma escolha intencional, supondo um procedimento informal. Sampierre (2006) complementa que na referida amostra "...a escolha dos indivíduos não depende de que todos tenha a mesma probabilidade de ser escolhido, mas da decisão de um pesquisador..." (p. 271). Os professores e gestores envolvidos na investigação pertencem ao turno de estudo e trabalhos matutinos e vespertinos, por tratarem de Educação Infantil e Ensino Fundamental Anos Iniciais.

\section{4.-Técnicas de coleta de dados.}

Numa pesquisa a coleta de dados é um momento primordial e indispensável, pois a mesma tem como objetivo coletar o maior numero de informações possíveis sobre 0 contexto estudado. Assim sendo, o pesquisador utilizou como técnica de investigação a observação direta (estruturada) através de uma ficha de observação onde o pesquisador estabeleceu indicadores e através dos mesmos observou a existência de alguns elementos essencial para à evidencia de acessibilidade nas escolas pesquisadas.

\section{4.-Análise de resultados.}

Para esta investigação foram coletados, analisados e interpretados dados advindo de ficha de observação das estruturas físicas das escolas, entrevistas com professores, Secretários de Educação, Gestores, todos representados na mesma como sujeitos participantes da rede municipal de ensino. Para a análise dos resultados foram utilizados Técnica de Análise de Dados. A pesquisa possibilitou muitas informações e reflexões inerente a inclusão física numa visão de acessibilidade para pessoas com deficiência física na rede municipal de ensino. 
Objetivo 01: Analisar o processo inclusivo das escolas da rede municipal de ensino para os deficientes físicos.

No propósito de analisar o processo inclusivo das escolas da rede municipal de ensino para pessoas com deficiência física, questionou-se os professores, gestores das escolas A, B, C e D e Secretária de Educação sobre alguns elementos que evidenciam este processo. O resultado das entrevistas dos pesquisados, encontramse abaixo com suas respectivas análises.

Categoria de professores - Análise da entrevista

Com interesse de conhecer a visão dos pesquisados no que se refere aos obstáculos para a inclusão das pessoas com deficiência física, perguntou-se aos professores das escolas A, B, C e D na 11a questão da entrevista: Em sua visão há realmente obstáculo para inclusão de pessoas com deficiência física nas escolas municipais? Dos 34 professores entrevistados, 26(vinte e seis) responderam que sim, enquanto 08 (oito) responderam que não.

Nota-se com as respostas dos professores das escolas A, B, C e D, que as referidas escolas encontram-se despreparadas para atender os alunos com deficiência física, implicando diretamente no processo inclusivo desses alunos, pois uma escola só pode se considerar inclusiva quando esta se propõe a atender em todas as dimensões os alunos com necessidades especiais, conforme é evidenciado por FERREIRA,( 2003) apud FIGUEREIDO, (2010) "A inclusão é uma força cultural para a renovação da escola, mas para que aquela tenha sucesso, esta deve torna-se comunidade consciente ..." (pag. 75).

Conforme respostas dos entrevistados acima, evidencia-se ainda, que as escolas supracitadas não correspondem com as particularidades dos seus alunatos. Contrariando o que diz a Lei 7.853 de 24 de outubro de 1989 no seu Art. 20:

Ao Poder Público e seus órgãos cabe assegurar às pessoas portadoras de deficiência o pleno exercício de seus direitos básicos, inclusive dos direitos à educação, à saúde, ao trabalho, ao lazer, à previdência social, ao amparo à infância e à maternidade, e de outros que, decorrentes da Constituição e das leis, propiciem seu bem-estar pessoal, social e econômico. (Brasil, 1989, p. 01).

A violação dos direitos supracitada torna-se notório nesta investigação, diante dos fatos constatados através dos instrumentos de coleta de dados, percebe-se uma significativa precariedade quanto ao oferecimento de dispositivos que confirme a inclusão dos alunos com deficiência física nas escolas pesquisadas, estes implicam diretamente no processo de desenvolvimento destes alunos, tornando-os mais distante de uma ambiente acolhedor conforme suas especificidades.

Categoria de gestores: Com interesse de conhecer a visão dos pesquisados no que se refere aos obstáculos para a inclusão das pessoas com deficiência física, perguntou-se aos gestores das escolas A, B, C e D da rede Municipal de Ensino na $11^{\mathrm{a}}$ questão da entrevista: Em sua visão há realmente obstáculo para inclusão de pessoas com deficiência física nas escolas municipais? Dos entrevistados 03 (três) responderam que sim, enquanto 01 (um) respondeu que não.

Conforme as respostas dos gestores, as referidas escolas não encontram adequados para receber os alunos com deficiência física, implicando dizer que a visão dos mesmos não contraria as dos professores, conforme visto anteriormente, neste 
sentido, as respostas dos entrevistados vem confirmar a sociedade a falta de condições acessíveis arquitetônica das escolas pesquisadas, contrariando 0 artigo 206 da Constituição Federal que estabelece: "O ensino será ministrado com base nos seguintes princípios: I - igualdade de condições para 0 acesso e permanência na escola". (Brasil, 1988, p.42).

Neste aspecto a escola tem como competências não só oferecer um ambiente propício, mas condições para que o aluno consiga permanecer no ambiente escolar, implicando afirmar que atitudes simples como construção de rampas, banheiros adaptados, corrimões, dentre outros dispositivos oportuniza acesso aos ambientes físicos da escola, favorecendo aos alunos com deficiências físicas ou mobilidades reduzida a oportunidade de se sentirem em condições de igualdade.

Percebe-se nas respostas das entrevistas realizadas aos gestores das escolas $A$, $B, C$ e D da rede municipal de ensino, que a limitação arquitetônica não favorecem a interação das crianças com deficiência físicas aos ambientes da escola, conforme enfatiza Figueiredo, "A escola é um desses espaços privilegiados de interação social...É possibilitar a oportunidade da criança fazer tudo que todo mundo faz, mas não necessariamente do mesmo modo que todo mundo faz." ( Figueiredo, 2010, p.69)

Categoria de Secretário de Educação: no propósito de conhecer a visão da Secretaria Municipal de Educação de Alto Alegre - Brasil no que se refere aos obstáculos para a inclusão das pessoas com deficiência física, perguntou-se na $11^{\mathrm{a}}$ questão da entrevista: Em sua visão há realmente obstáculos para a inclusão de pessoas com deficiência física nas escolas municipais? A entrevistada respondeu que sim, mediante este resultado, configura-se que a inclusão dos alunos com deficiência física do município de Alto Alegre encontra-se comprometida pela ausência de mecanismo que viabilize este processo, conforme explicita-se Schirmer:

Com base nos princípios do desenho Universal e da Lei $n^{0} 10.098 / 00$, toda escola deve promover ambiente acessível, eliminando as barreiras arquitetônicas e adequando os espaços que atendam a diversidade humana. Recentemente também foi promulgado 0 Decreto $\mathrm{n}^{0}$ 5.296/2004 que "estabelece normais gerais e critérios básicos para a promoção da acessibilidade das pessoas com deficiência física ou mobilidade reduzidas e dá providencias". Este decreto estipula um prazo de 30 meses, para que os lugares públicos organizem seus espaços de forma a torná-los acessíveis. (Schirmer, 2007, p. 105).

Neste sentido, a escola precisa reafirmar sua concepção educacional, visando a transformação de atitudes e valores que rompem os paradigmas da exclusão nas escolas, para tal, busca-se na concretização da Política Nacional de Inclusão, visualizar o fortalecimento das ações que norteiam o processo inclusivo das escolas como também, as atitudes de uma escola inclusiva, conforme enfatiza

A concretização da política de inclusão já se torna perceptível quando as redes de ensino começam a se organizar para perceber e oferecer as condições de aprendizagem a todo o seu alunado. A escola que entendeu o princípio da inclusão, sabe que precisa rever práticas pedagógica, não porque a gora tem a presença de um aluno com deficiência na sala de aula, mas porque compreendeu que não pode 
ignorar a diferença de seus alunos. Esta mudança terá efeitos profundos sobre a sociedade e sobre as dinâmicas das interações entre os cidadãos brasileiro.( Figueiredo, 2010, p. 67).

Portanto visualiza-se, que a Política Nacional de Educação Inclusiva (2008), propõem a mudança de valores, atitudes e práticas educacionais no intuito de atender todos os alunos, sem nenhum tipo de discriminação, afirmando a qualidade de atendimento na educação.

Categoria de Professores, Gestores e Secretária de Educação: na 14a questão da entrevista, perguntou-se aos Professores, Gestores das escolas A, B, C e D e Secretária de Educação: Como membro desta escola você está devidamente preparada (o) para atender os alunos com deficiência física? O resultado de referida questão evidenciou que dos 34 (trinta e quatro) professores entrevistados, 04 (quatro) responderam que sim, enquanto 30 (trinta) responderam que não. Dos 04 gestores, 03 (três) responderam que não enquanto 01 (um) respondeu que sim; já a resposta da Secretaria de Educação foi não.

Com a evidencia negativa quanto ao despreparo dos profissionais representantes da rede municipal de ensino de Alto Alegre/Brasil no atendimento aos alunos com deficiência física, configura-se que 0 sistema não encontra-se estruturado didaticamente no intuito de oferecer aos mesmos recursos humanos e materiais que podem institui elementos fundamentais no processo de aprendizagem, constituindo barreiras na inclusão desses alunos, entende-se ainda, que a preparação desse profissional deverá ser 0 ponto principal para se promover uma educação de qualidade para todos os alunos.

Os educadores precisam perceber que o contexto escolar fará toda a diferença na vida dos alunos com deficiência física, são as seguridades que fazem com que as diferenças apareçam e cobrem respostas variadas do meio, sendo assim, 0 professor precisa conhecer 0 aluno para que sua formação seja baseada nas especificidades de sua clientela. Segundo Cavalcante e apud Figueiredo:

Diante desses alunos, professores, algumas vezes, se posicionam de forma restrita, motivados pela dificuldade de compreender como atuar junto a eles. É fato que a formação inicial da maioria dos professores ainda traz a marca da "quase total" ausência de discussões sobre esse contingente de pessoas, 0 que os deixa inseguros para 0 trabalho. (Cavalcante, 2003 , apud Figueiredo 2010, p.82).

Portanto, evidencia-se com a síntese dos resultados das entrevistas realizadas com os Professores, Gestores das Escolas A, B,C, e D e Secretária de Educação da rede Municipal de Ensino, que a maioria dos profissionais da referida rede encontram-se inseguros na atuação com os alunos com deficiência física. Atribui-se a esta evidencia uma proposta que direcione o contingente de professores e Secretário de Educação, para uma formação continuada na área de Atendimento Educacional Especializado, realizados nas salas de recursos multifuncionais.

Categoria de Professores, Gestores e Secretária de educação: na 15ª questão da entrevista, perguntou-se aos professores, gestores das escolas $A, B, C$ e D e secretária de educação: Você já realizou algum curso na área de educação especial? Dos 34 professores 18(dezoito) responderam que sim, enquanto 16 (dezesseis) 
responderam que não. Dos 4(quatro) Gestores 3(três) responderam que sim, e 1 respondeu que não. A Secretária Municipal de Ensino respondeu não.

Analisa-se através dos resultados das entrevistas realizadas com os Professores, Gestores das Escolas A, B,C e D que a maioria dos professores e gestores da rede municipal de ensino de Alto Alegre/Brasil, tem cursos na modalidade de Educação Especial.

Apesar do resultado positivo da formação dos professores, contradiz a sua atuação, pois estão preparados com capacitações, mas infelizmente inseguros quanto ao atendimento aos alunos com deficiência física, conforme ficou detectado na referida entrevista. Neste sentido, imite-se uma indagação: Será se os cursos realizados pelos profissionais foram condizentes com as necessidades evidenciadas pelos mesmos em sala de aula?

A confirmação para a sociedade da falta de práxis, relação teoria e pratica, dos professores, gestores das escolas A, B, C e D, e da Secretária de Educação da rede Municipal de Ensino, no atendimento aos alunos com necessidades especiais, trazem a marca do momento que vivem as escolas da rede do município de Alto Alegre/Brasil, configurando um cenário de descaso a formação continuada dos professores e demais profissionais que atuam na rede supracitada.

Categoria de Professores, Gestores e Secretária de educação: na 16a questão da entrevista, perguntou-se aos professores, gestores das escolas A, B, C e D e secretária de educação: Como você concebe a inclusão de alunos com deficiência físicas na escola? "Principais respostas: "muito importantes" com boa receptividade" "necessário para a formação acadêmica, moral, afetiva e social ...vejo como um desafio" "É maravilhoso, o que falta são subsídios"

Percebe-se com os resultados das respostas dos professores, gestores das escolas A, B, C, e, D e Secretária de Educação, que ambos concebem a inclusão como uma ação necessária para a inserção dos alunos nas escolas. Figueiredo (2010) afirma que:"[...]A prática de inclusão implica no reconhecimento das diferenças dos alunos e na concepção que a aprendizagem é construída em cooperação a partir da atividade do sujeito diante das solicitações do meio" (pag. 66).

Neste sentido, evidencia-se a relevância da inclusão como um processo coletivo, que visa oferecer ao aluno um ambiente cooperativo, reconhecendo suas limitações e diferenças.

Categoria de Professores, Gestores e Secretária de Educação: na 17a questão da entrevista, perguntou-se aos pesquisados: A escola apresenta algum projeto voltado a inclusão escolar dos alunos com deficiência física? Dos 34 professores entrevistados, 06 (seis) responderam que sim, enquanto 28 (vinte e oito) responderam que não. Dos 04(quatros) gestores entrevistados, 01 respondeu que sim enquanto 03(três) responderam não. A Secretária Municipal de Educação, respondeu "não, apesar de fazer parte do sistema de ensino, mas não entende que precise desenvolver projetos para atendimento dos alunos com deficiência física, tendo em vista que as escolas é que são incumbidas deste processo"

Com as respostas dos entrevistados supracitados, percebe-se que as escolas $A, B$, $C$ e D da rede municipal de ensino de Alto Alegre/Brasil, encontram-se desprovidas de estratégias que viabilize a inclusão dos alunos com deficiência física. 
O processo inclusivo das pessoas com deficiência física torna uma possível realidade quando vivenciada por seus pares, alternativas acessíveis no cotidiano escolar.

Categoria de Professores, Gestores e Secretária de educação: na 19a questão da entrevista, perguntou-se aos pesquisados: Na sua percepção quais as dificuldades existentes nas escolas publicas quanto a inclusão dos alunos com deficiência física? Resumo das principais respostas de todas as categorias: "Profissionais qualificados" "Formação específicas para Professores"; "Ambiente adequado arquitetonicamente"; "Omissão do Poder Publico", "Ausência de Projetos Pedagógicos", "Falta de comprometimento do Sistema de Ensino".

Configura-se nas respostas dos entrevistados, que as escolas da rede municipal de ensino de Alto Alegre/Brasil encontram-se desprovidas de alguns elementos indispensáveis para a promoção da inclusão escolar.

Neste aspecto, a pesquisa convida para uma análise que inferi diretamente na formação dos profissionais que atuam na rede municipal de ensino, tal como a evocação do Ministério Publico para que se possa fiscalizar de forma mais precisa a falta de dispositivos necessários para a inclusão dos alunos com deficiência, como também, a omissão do próprio sistema de ensino e a falta de estratégias, como projetos específicos, que viabilize a inclusão desses alunos nas escolas A, B, C e D compositoras da rede municipal de ensino de Alto Alegre/Brasil.

A síntese dos resultados supracitados demonstra nos obstáculos apontados pelos entrevistados que a inclusão nas escolas A, B, C e D segrega e discrimina 0 contingente de alunos com deficiência física, principalmente no que concerne negarIhe a possibilidade de usufruir de ferramentas existentes no âmbito escolar.

Nos dados coletados possibilita-se perceber a "Ausência de Projetos Pedagógicos" nas escolas pesquisadas como um deficit no oferecimento de oportunidades pedagógicas a todos os alunos inclusos nas escolas $A, B, C$ e $D$ da rede municipal de ensino, Gardner (1994) enfatiza a importância do projeto para os alunos na aquisição de conceitos e habilidade: “...um projeto fornece uma oportunidade para os estudantes disporem de conceitos e habilidades previamente dominadas a serviço de uma nova meta e empreendimento" (pag. 189) assim sendo, este caracteriza um relevante elemento no processo de aquisição de aprendizagem dos alunos inclusos nas escolas pesquisadas. Portanto e conforme resultado das entrevistas, as referidas escolas não encontram-se respaldadas com projetos pedagógicos, contrariando a Declaração de Salamanca, Brasil (1994, p. 4) ressaltam a aprendizagem como processo humanizados à todas as crianças.

Categoria de Professores, Gestores das escolas A, B, C e D e Secretária de Educação: No intuito de saber se as escolas da rede municipal de ensino de Alto Alegre/Brasil, contemplam em sua estratégia de atuação a inclusão de todos os alunos nas atividades físicas, perguntou-se na $18^{a}$ questão aos professores, Gestores das escolas A, B, C e D e Secretária de Educação: As crianças com deficiência física praticam atividades físicas junta às outras crianças? Dos 34 professores entrevistados, 20(vinte) responderam que sim, enquanto 14(quatorze) responderam que não. Dos 04 (quatro) gestores entrevistados, 02(dois) responderam que sim, enquanto 02(dois) responderam que não. A Secretaria de Educação respondeu: "Sim. Embora reconheço que as escolas necessitam de uma organização mais precisa quanto a estas especificidades". 
A pesquisa demonstrou através das entrevistas realizadas com os professores, gestores e Secretário da Educação, que as escolas da rede municipal de ensino estão atentos quanto ao processo de inclusão dos alunos com deficiência física no que concerne a participação dos mesmos nas atividades de educação física. Neste sentido, Omete, afirma que:

Quanto mais se dá ênfase à formação integral do cidadão, com destaque nos convívios entre os diferentes como um importante ingrediente nessa empreitada, mas parece convincente a proposta de inclusão escolar.(Omete, 2004, p.3).

Assim sendo, a escola não é visualizada como um ambiente segregador, mas sim, um ambiente que promove a inclusão, de forma que cada criança é percebida mediante suas especificidades e explorada como tal.

Análises das observações realizadas nas Escolas A, B, C e D: na investigação, com intuito de obter informações in loco inerentes ao Critério Inclusão nas escolas A, B, C e $D$ da rede municipal de ensino de Alto Alegre/Brasil, elaborou-se uma lista de indicadores no que concerne aos aspectos relacionados à inclusão de pessoas com deficiência física nas 04 (quatro) escolas investigadas.

O critério de Inclusão observados nas Escolas analisou 05 (cinco) indicadores; $01^{0}$ (primeiro) indicador buscou verificar se "as escolas possuem professores qualificados para atuar na educação inclusiva". O resultado encontrado indica que a escola A, B, C e D possuem professores qualificados para atuarem na educação inclusiva.

$\mathrm{Na}$ visão da pesquisadora a qualificação profissional é entendida como uma preparação do indivíduo para desempenhar suas aptidões ao qual foi designado. Sendo assim, o professor qualificado na educação inclusiva torna se uma ferramenta assídua no processo de inclusão, assumindo saberes no que concerne a forma de lidar com as diversidades existentes entre os alunos.

Neste sentido, a qualificação profissional é visualizada essencialmente numa ação de construção de si própria, onde parte da premissa que o professor necessita conceber a qualificação como uma atividade de aprendizagem situada em tempos, espaços limitados e precisos, no encontro com as relações de pluralidade, envolvendo 0 paradigma de inclusão. Assim sendo, Moita enfatiza a necessidade de perceber esta qualificação de forma coletiva:

Ninguém se forma no vazio. Formar-se supõe troca, experiência, interações sociais, aprendizagem, um sem fim de relações. Ter acesso ao modo como cada pessoa se forma é ter em conta a singularidade da sua história e, sobretudo, o modo singular como age, reage e interage com os seus contextos. Um percurso de vida é assim um percurso de formação, no sentido em que é um processo de formação. (Moita, 1992, p.115)

O $2^{\circ}$ (segundo) indicador observou se "as escolas oferecem cursos de formação continuada para os professores que atuam juntos aos alunos com deficiência física". De acordo com os resultados encontrados, as Escolas A, B, C e D não oferecem cursos de formação continuada para os professores que atuam juntos aos alunos com deficiência física. 
Ratifica-se nas observações acima a precariedade das escolas $A, B, C$ e D no oferecimento de cursos de formação continuada aos professores, contrariando 0 disposto na resolução 02 de 11 de setembro de 2001 do Conselho Nacional de Educação, que institui diretrizes Nacionais para a Educação Especial na Educação Básica, apontando a qualificação dos professores da educação especial como uma das ações necessárias para a concretização da educação inclusiva: $03^{\circ}$ (terceiro) indicador verificou se "as escolas possuem em suas estratégias de atuação a legislação que assegura o processo de inclusão da pessoa com deficiência física". Os resultados encontrados demonstram que as escolas $A, B, C$ e D não possuem em suas estratégias de atuação a legislação que assegura o processo de inclusão da pessoa com deficiência física.

Observou-se com a pesquisa que as escolas A, B, C e D, não utilizam em sua estratégia de atuação a legislação que assegura a inclusão dos alunos com deficiência física, confirmando a precariedade das referidas escolas quanto ao embasamento legal no atendimento aos alunos referidos alunos.

A Política Nacional de Educação Especial na Perspectiva da Educação Inclusiva Brasil,(2008) reconhece as dificuldades enfrentadas nos sistemas de ensino quanto ao processo inclusivo dos alunos com necessidades especiais, assim sendo, enfatiza nos seus objetivos a garantia da "articulação intersetorial na implementação das políticas públicas" (p.19), significando afirmar que as escolas estão respaldadas na busca de parcerias para o fortalecimento de suas estratégias quanto a legislação que respalda as mesmas em sua prática inclusiva.

Neste sentido, e diante dos resultados implicados pela a observação in loco, as referidas escolas necessitam reorganizarem seu projeto político pedagógico a fim de inserir em suas práticas a legislação específica que trata justamente do processo de inclusão dos alunos com necessidades especiais, em específico a deficiência física. O $4^{\circ}$ (quarto) indicador buscou verificar se "os gestores viabilizam meios para a efetivação do ensino inclusivo às pessoas com deficiência física". Os resultados obtidos revelam que os gestores das escolas A, B, C e D, não viabilizam meios para a efetivação do ensino inclusivo às pessoas com deficiência física.

Nas visitas in loco nas escolas supracitadas, não foi constatados nenhum mecanismo que caracterizassem a viabilização de meios para a efetivação do ensino inclusivo às pessoas com deficiência física, contrariando o disposto na Política Nacional de Educação Especial na Perspectiva da Educação inclusiva:

Os sistemas de ensino devem organizar as condições de acesso aos espaços, aos recursos pedagógicos e à comunicação que favoreçam a promoção da aprendizagem e a valorização das diferenças, de forma a atender as necessidades educacionais de todos os alunos.(Brasil, 2008, p. 14)

Neste sentido, implica afirmar o notório descaso das escolas $A, B, C$ e D quanto a inclusão dos alunos com deficiência física, configurando uma prática exclusiva e discriminatória, infringindo a Constituição Federal, Brasil, (1988), lei soberana do País. 


\section{5.-Conclusión.}

A investigação aqui apresentada propôs-se analisar a acessibilidade arquitetônica para os alunos com deficiência física da rede municipal de ensino de Alto Alegre/RR, refletindo sobre as escolas que estão ou não adaptadas e preparadas para este processo. A investigação foi respaldado em um estudo com base em um referencial teórico que aborda todo o assunto referente ao processo da pesquisa e um estudo de campo que juntos confirmam a inexistência de acessibilidade arquitetônica nas escolas da rede municipal de ensino de Alto Alegre/Brasil. As principais análises que compõem esta investigação científica fazem menção ao seguinte problema: $A$ acessibilidade arquitetônica significa a possibilidade de acesso das pessoas com mobilidade reduzida a qualquer lugar, com autonomia na participação nas atividades deste espaço. Assim sendo, os alunos com deficiência física da rede municipal de ensino de Alto Alegre/RR-Brasil têm acesso aos edifícios das escolas? Para tal, com 0 intuito de alcançar os desígnios da referida pesquisa, foram elaboradas e desenvolvidas estratégias de investigação para obter-se maiores elementos, capazes de explanar os objetivos e o problema da pesquisa.

Diante disso, o aporte desta pesquisa infere que a partir dos resultados obtidos na coleta de dados da investigação demonstra uma significativa irrelevância do sistema municipal de ensino no que concerne à promoção de acessibilidade arquitetônica para os alunos com deficiência física, como também, o comprometimento da inclusão destes alunos no processo educacional das escolas da rede municipal de ensino de Alto Alegre/Brasil.

Para tal, pretendeu-se com $01^{1}$ (primeiro) objetivo: Analisar o processo inclusivo das escolas da rede municipal de ensino para deficientes físico, constatou-se com a investigação que a inclusão dos alunos com deficiência física nas escolas A, B, C e D da rede Municipal de ensino de Alto Alegre/Brasil, encontram-se comprometidas, tendo vista a ausência de alguns dispositivos como: formação continuada, rampas, calçadas, atividades adaptadas ao currículo, espaço de livre circulação, projetos voltado a inclusão de deficientes físicos nas atividades propostas pelas escolas, imprescindível para 0 processo inclusivo dos referidos alunos. A pesquisa demonstrou ainda, que apesar da notória precariedade no que concerne a inclusão dos alunos, as escolas supracitadas, reconhecem a relevância da inclusão como um processo coletivo indispensável na promoção de um ambiente cooperativo, interativo e acima de tudo, sem limitações e diferenças.

No $2^{\circ}$ (segundo) objetivo tem por competência observar se as escolas da rede municipal de ensino contemplam em suas estratégias de atuação os recursos de acesso para alunos com deficiência físicas, com os resultados alcançados, evidenciou-se na investigação a precariedade nas dependências físicas das escolas $A, B, C$ e D da rede municipal de ensino de Alto Alegre /Brasil, principalmente a ausência de banheiros adaptados, dispositivos ou mobiliário adequado e espaços de livre para circulação, rampas que dá acesso a rotas indispensáveis para execução de atividades, como 0 acesso a quadra de esporte. Neste sentido, a ausência de um ambiente acessível compromete significadamente a inclusão dos alunos com deficiência fica nas escolas supracitadas. 
O espaço escolar não deve ser considerado como um mero ambiente físico, mas um lugar que propicia a construção de relações sociais, de relações com o aprendizado e também com o meio. Este espaço deve levar em consideração a diversidade humana, assim sendo, os elementos que o compõe são indispensáveis como meio articulador para a efetivação do processo inclusivo.

O $3^{\circ}$ (terceiro) objetivo comprometeu-se em Observar a legislação específica para acessibilidade das pessoas com deficiência nas escolas publicas. Constatou-se na observação da legislação específica para acessibilidade das pessoas com deficiência nas escolas A, B C e D da rede municipal de ensino, que as escolas têm conhecimento da Política Nacional de Educação Inclusiva e creditam na mesma uma alternativa para aquisição de mecanismo que viabilize o processo inclusivo nas referidas escolas, tomando por base a dialética da referida política.

Neste sentido, busca-se através da legislação a garantia de uma educação de qualidade, onde todos, sem exceção, tenham direito ao ensino, a convivência e acima de tudo, o direito de andar livremente, sem barreiras que o impeçam de explorar todos os espaços físicos das escolas, independente de seu tamanho, mas que ofereça o mínimo do exigido na legislação, a acessibilidade.

No $4^{\circ}$ (quarto) objetivo, que tem como alçada relacionar a acessibilidade para uma boa convivência social e inclusão escolar, confirmou-se na investigação que ao relacionar a acessibilidade para uma boa convivência social e inclusão escolar a sociedade preocupa sobremaneira quanto a inclusão dos alunos com deficiência física inseridos nas escolas, como também um ambiente acessível corresponde significadamente ao bem estar social de qualquer criança, principalmente as crianças com deficiência física.

A acessibilidade consente as crianças com deficiência física terem uma vida social ativa: trabalharem, estudarem e conviverem socialmente como qualquer outra pessoa, um ambiente acessível é indispensável para o desenvolvimento cognitivo, físico e principalmente, para a efetivação da cidadania. Para (Dischinger et al 2004 p.160)) "Todos os ambientes e equipamentos devem possibilitar seu uso e a realização de atividades com conforto e segurança, de acordo com as necessidades especiais de cada indivíduo..."

Assim, a acessibilidade e a convivência social faz-se necessário no sentido de 0 aluno idealizar sua comunicação, sua linguagem, como também conceber sua autonomia como um direito garantido e respaldado em legislações específicas.

No $5^{\circ}$ (quinto) e último objetivo, tem a incumbência de analisar a acessibilidade arquitetônica nas escolas municipais de Alto Alegre, constatou-se com a investigação, a inexistências de acessibilidade arquitetônica nas escolas A, B, C e D da referida rede, principalmente no que concerne: a estrutura física adequada para atender as pessoas com deficiência física; as modificações perpassadas pelas escola no intuito de oferecer acesso e locomoção a todos os ambientes da escola, como rota acessível, rampas no portão de entrada, calçadas com inclinação adequada, banheiros adaptados.

A ausência desses elementos nas escolas investigadas compromete sobremaneira a inclusão dos alunos com deficiência física inseridos nas escolas e que necessitam deste espaço para que tenham livre acesso, sem dificuldades ou barreiras, possam circular livremente nas dependências das escolas. 
Para que seja garantida e assegurada a acessibilidade nos prédios públicos, neste caso, a escola, promulga-se o decreto federal 5.296/2004 de 2 de dezembro, Brasil (2004), o mesmo constitui normas básicas para a promoção da acessibilidade e a Lei 10.098/00, que estabelece normais gerais e critérios básicos para promoção da acessibilidade das pessoas portadoras de deficiência ou com mobilidade reduzida.

A inexistência de acessibilidade arquitetônica nas escolas municipais compromete a legislação que garante o direito de acesso, circulação e utilização dos espaços públicos pelas pessoas com deficiência física ou mobilidade reduzida.

Conforme o referencial teórico em estudo, e evidencias de experiências juntos de trabalhos juntos as pessoas com deficiência física, está comprovado que a acessibilidade promove a quebra de barreiras e de limites aos alunos com deficiência física, permite a condição de alcance, percepção e entendimento para a utilização com segurança e autonomia os espaços da escola, ofertando igualdade de oportunidade e participação plena a todos os deficientes físicos.

Em resposta ao problema proposto por esta pesquisa: $A$ acessibilidade arquitetônica significa a possibilidade de acesso das pessoas com mobilidade reduzida a qualquer lugar, com autonomia na participação nas atividades deste espaço. Os alunos com deficiência física da rede municipal de ensino de Alto Alegre/RR-Brasil têm acesso aos edifícios das escolas? Inferimos que diante dos resultados supracitados, não se evidencia acesso aos edifícios das escolas A, B, C e D que compõem a rede municipal de ensino de Alto Alegre/Brasil, pelos alunos com deficiência física.

Neste sentido, implica afirmar que a ausência de acessibilidade arquitetônica nas escolas A, B, C e D da rede municipal de ensino de Alto Alegre/Brasil, compromete sobremaneira o processo de inclusão dos alunos com deficiência física inseridos na referida rede. Embora a legislação verse especificamente a garantia de acessibilidade nos prédios públicos, as referidas escolas não correspondem com as particularidades dos seus alunatos, principalmente no que concerne a acessibilidade arquitetônica, tornando-se notório a precariedade quanto ao oferecimento de elementos determinantes para a efetivação da inclusão das pessoas com deficiência física nas escolas.

\section{6.-Referencias.}

Aranha, M.S.F. (2001). Paradigmas de relação da sociedade com as pessoas com deficiência. Revista do ministério público do trabalho, Brasília, ano IX, n. 21, mar.

Bersch, R. (2006). Introdução à tecnologia Assistiva. Texto complementar distribuídos em curso Tecnologia Assistiva. Disponível em .www.assitiva.com.br. RS.

Brasil. (2004). Associação brasileira de normas técnicas. Nbr 9050: Acessibilidade a edificações, mobiliário, espaços e equipamentos urbanos. Rio de Janeiro.

. Constituição da República Federativa do Brasil, 1988. Disponível em: <http:// www.planalto.gov.br>. Acesso em: 10 set. 2018. 
(2001) conselho Nacional de Educação. Câmara de Educação Básica. Resolução CNE/CEB 2/2001. Diário Oficial da União, Brasília, 14 de Setembro. Secção $1 \mathrm{E}$ (p. 39-40).

. Lei 10.048 de 8 de novembro de 2000. Dá prioridade à pessoas que especifica e dá outras providências. Disponível em: <http:// www.mec.gov.br. Acesso em: 10 ago. 2010.

Mantoan, M.T., Eglér; Pietro, R.G., Arantes, V.A. (Org.). (2006). Inclusão escolar: pontos e contrapontos. São Paulo: Summus.

Nogueira, N.R. (2001). Pedagogia dos Projetos: uma jornada interdisciplinar rumo ao desenvolvimento das múltiplas inteligências. São Paulo: Érica.

Omete, S.(2004). Inclusão: intenção e realidade. Marília: Fundepe.

Sampieri, R.H., Collado, C.F., Lucio, P.B. (2008). Metodologia de La Investigación. 4 ed, Mexico: McGrawHill. 